\title{
Ordem Pública: o Direito Internacional Privado e a Constituição
}

\author{
Raphael Carvalho de Vasconcelos*
}

\begin{abstract}
Resumo:
A ordem pública, instituto inerente ao conflito de leis e de jurisdições, exige a proteção da moralidade local por meio do óbice à aplicação da lei indicada pela regra de conexão à solução da lide multiconectada ou à homologação de sentenças e concessão de exequatur a cartas rogatórias estrangeiras incompatíveis com os padrões sócio-culturais do foro. Esse instrumento reativo tem na relatividade a principal característica e sua aferição fica, por inexistirem parâmetros objetivos aparentes à dotação de seu conteúdo, freqüentemente a cargo da discricionariedade judicial. No traslado do discurso dos direitos humanos ao direito internacional privado e, especificamente, à caracterização da ordem pública, observa-se a possibilidade de se estruturarem parâmetros capazes de estabilizar o instrumento obstador e de orientar o magistrado na proteção da moral de seu ordenamento.
\end{abstract}

Palavras-chave: ordem pública; direito internacional privado; constituição;

\begin{abstract}
:
The international private law public policy, typical instrument of the conflict of laws and conflict jurisdiction doctrine, requires protection for local morality by means of denying the applicability of the law appointed by the conflict rule to the solution of the legal suit or to the recognition of foreigner judgments inconsistent with social and cultural standards of the sought court. This institute is commonly described by doctrine mainly as for its relativity and - being no concrete rules to establish its content available - the identification of the applicable circumstances is very often under judicial discretionarity. The conduction of the human rights dialogic construction to the international private law doctrine and, specifically, to characterize the international private law public policy, it is possible to verify a technique to establish the fluid character of the institute.
\end{abstract}

Key-words: public policy; private international law; constitution;

\section{Introdução}

No conflito de leis no espaço, a atuação do direito internacional privado no estabelecimento de regras para a solução de litígios parte do pressuposto da extraterritorialidade das leis e permite que, ao menos em situações excepcionais, os sistemas legais vislumbrem e até exijam a aplicação da lei estrangeira no território a eles submetido.

Quando dispositivos de diferentes fontes legais são convocados à solução do caso concreto e o aplicador do direito se utiliza das regras estabelecidas pelo direito internacional privado para definir a lei aplicável ou para decidir quanto à possibilidade de 
concessão de efeitos internamente a pronunciamentos alienígenas, as distintas soluções apresentadas pelos sistemas legais envolvidos podem levá-lo a posicionar-se de forma atentatória aos preceitos morais e jurídicos localmente cogentes.

A proteção da ordem pública do direito internacional privado consiste, nesse contexto, no resguardo do núcleo moral inegociável de determinado ordenamento por meio da aferição de atentado à ordem pública e consubstancia condicionante à geração de efeitos no foro por direito ou pronunciamento jurisdicional alienígena. $\mathrm{O}$ instituto funciona, desse modo, como verdadeiro escape garantidor dos valores essenciais do foro.

O gradativo e secular desenvolvimento da doutrina internacionalista não logrou estabelecer, entretanto, técnica segura e previsível à dotação de conteúdo à ordem pública, é dizer, à sistematização da determinação do rol de situações, às quais a exigência de proteção da moral local incidiria.

A investigação aqui proposta parte da análise da perspectiva histórica e atual do princípio da proteção da ordem pública do direito internacional privado - especialmente no que se refere aos motivos de sua instabilidade de conteúdo - e pretende apresentar uma técnica hábil a dotar a exceção de um núcleo estável e, portanto, capaz de trazer maior segurança e previsibilidade às situações jurídicas multiconectadas.

Tal objetivo tem como vértice conceitual a perspectiva da análise da transposição do debate conciliador ente o universalismo e o multiculturalismo da doutrina da proteção internacional dos direitos humanos refletida na positivação dos direitos fundamentais contidos na Constituição Federal à orientação da conceitualização e delimitação da ordem pública do direito internacional privado e à análise de sua aplicação como parâmetro de aferição da necessidade de se proteger a moralidade do ordenamento jurídico instado a permitir efeitos internos a direito ou a decisões judiciais estrangeiras.

Nesse sentido e como instrumental teórico compatível com a construção da proposta descrita, apresenta-se a hermenêutica diatópica idealizada por Boaventura de Sousa Santos, verdadeira alternativa cooperativa de diálogo intercultural, complementada pelo conceito de dignidade humana das teorias de Ronald Dworkin e harmonizada com as teorias no maximalismo e do minimalismo moral de Michael Walzer. 


\section{A Ordem Pública no Direito Internacional Privado}

As duas acepções mais comuns da expressão "ordem pública"1 referem-se às normas internas que limitam a autonomia privada e ao instituto do direito internacional privado que permite o afastamento do direito estrangeiro pelo aplicador do direito tanto na não aplicação da lei indicada pela regra de conexão como na negativa de homologação de sentenças ou concessão de exequatur a cartas rogatórias provenientes do exterior. Essa multiplicidade de sentidos acaba semeando, contudo, discórdia doutrinária na delimitação de conteúdo e de limites a sua aplicação.

Nesse sentido, é de se perceber que da dificuldade de se estabelecer um rol taxativo de circunstâncias, nas quais se aplicaria a exceção da ordem pública, extrai-se a principal característica do instituto apontada pela doutrina: a relatividade. A ordem pública do direito internacional seria, assim e portanto, relativa, instável ${ }^{2}$, dependeria de sua incidência no caso concreto para ser preenchida de conteúdo e não poderia ser, desse modo, prédeterminada, concebida anteriormente a sua aplicação.

Valendo-se desse parâmetro, torna-se possível concluir que ao se estabelecer a indefinição prévia do rol de circunstâncias sujeitas à aplicação deste "remédio"”3 do direito internacional privado como premissa, seria de se afirmar, consequentemente, que o legislador não enumerou os casos de afastamento do direito alienígena, mas tão somente permitiu que tal repulsa ocorresse e deixou a cargo da discricionariedade judicial ${ }^{4}$ a decisão acerca da conveniência ou não do uso do instrumento ${ }^{5}$.

\footnotetext{
* Mestre em Direito Internacional pela Universidade de São Paulo, Mestre em Direito Internacional pela Universidade do Estado do Rio de Janeiro, Doutorando em Direito Internacional pela Universidade do Estado do Rio de Janeiro, professor da Universidade Federal Rural do Rio de Janeiro, Advogado. Contato: raphaelvasconcelos@ig.com.br

${ }^{1}$ CASTRO, Amílcar de. Direito internacional privado. Rio de Janeiro: Forense, 2005. p. 236. no que se refere à ordem pública no âmbito do direito internacional privado confere a Bouhier sua primeira elaboração conceitual e a Savigny sua primeira sistematização teórica.

${ }^{2}$ SAVATIER, , René. Cours de droit international privé. Paris: Librarie Générale de Droit et de Jurisprudence, 1947. p. 218.

${ }^{3}$ NIBOYET. J.-P. Notions sommaires de droit international privé en vue de l'examen de licence. Paris: Recueil Sirey, 1937. p. 136.

${ }^{4}$ RECHSTEINER, Beat Walter. Direito internacional privado - teoria e prática. São Paulo: Saraiva, 2007. p. 172.

${ }^{5}$ CASTRO, Op. cit., nota 01, p. 273.
} 
À autoridade judicial competiria, portanto, exclusivamente e no caso concreto, a determinação das situações jurídicas que exigiriam a aplicação do instituto da ordem pública como óbice ao direito estrangeiro ${ }^{6}$. Restaria indagar, todavia, quais seriam os limites dessa discricionariedade ou, ainda, se haveria limites a essa atuação.

Ainda que a doutrina aponte que a atividade jurisdicional na aplicação da ordem pública do direito internacional privado estaria vinculada aos "princípios consagrados pelas instituições e pela opinião pública mais 'saudável' (saine) do país", o que poderia ser resumido nos princípios jurídicos e costumes de uma determinada ordem jurídica, subsistiria considerável margem à submissão de seu conteúdo ao arbítrio do julgador. Exatamente nesta possibilidade de quase absoluta sujeição às convicções pessoais do magistrado se encontra o maior dos desafios à sistematização da aplicação da ordre public e a grande ameaça ao correto funcionamento das regras de direito internacional privado.

A falta de critérios previamente estabelecidos daria margem a aplicações equivocadas do instituto pelos magistrados e tais circunstâncias verificar-se-iam, certamente, mais em situações de excesso que de omissão. O exagero na identificação de situações que se enquadrariam no modelo de atentado à ordem pública do foro é frequentemente denunciado pela doutrina - brasileira e estrangeira - na análise de julgados ${ }^{8}$, os quais acabam, muitas vezes, refletindo absoluto desconhecimento da matéria pelos tribunais 9 .

No atual panorama de crescente aumento do número de relações multiconectadas resultado, principalmente, do incremento do comércio internacional, da maior facilidade e rapidez de locomoção e dos avanços tecnológicos na área das telecomunicações - torna-se insustentável o encerramento dos judiciários dos países em seus ordenamentos jurídicos como que em uma muralha intransponível e já se torna possível verificar avanços na

\footnotetext{
${ }^{6}$ DOLINGER. Direito internacional privado: parte especial - Direito civil internacional - vol. II - Contratos e obrigações no direito internacional privado. Rio de Janeiro: Renovar, 2007. p. 137.

${ }^{7}$ Ibid. p. 137.

${ }^{8}$ FERREIRA, Vasco Taboada. Princípios fundamentais dos sistemas de direito internacional privado português e brasileiro. Braga: Livraria Cruz, 1960. p. 22.

${ }^{9}$ STRENGER, Direito internacional privado. São Paulo: Ltr, 2005. p. 416.
} 
tolerância ao direito alienígena principalmente em tribunais mais integrados como aqueles dos Estados das comunidades européias ${ }^{10}$.

Cumpre ressaltar, finalmente, que não apenas os judiciários estatais devem aplicar a exceção de repulsa ao direito estrangeiro e são, conseqüentemente, responsáveis pela determinação de conteúdo da ordem pública do direito internacional privado. Também outros meios jurisdicionais de solução de controvérsias, como a arbitragem internacional privada $^{11}$, participam ativamente desse processo aplicando o instituto e construindo seus limites.

\section{O Global, o Local e a Modernidade}

O discurso filosófico predominante nas ciências sociais se encontra hoje altamente pautado na superação da modernidade. O incômodo causado pela falta de respostas às mazelas humanas e pela dificuldade de se colocar aquilo que é logicamente racionalizado em prática está exatamente no cerne do debate pós-moderno, ainda que o próprio conteúdo desse termo, criado à luz das angústias modernas ${ }^{12}$, seja colocado em xeque, contestado e considerado, por muitos, impróprio e superficial ${ }^{13}$.

No direito, especificamente, o prefixo indicativo desta busca por uma superação hábil a trazer respostas concretas a suas faltas e lacunas aderiu principalmente ao pensamento jurídico tecnicista, mecânico, codificado, é dizer, ao positivismo ${ }^{14}$. Póspositivismo se tornou, nessa toada, a vertente jurídica da pós-modernidade, mas a tentativa de se criar algo inovador acabou apenas potencializando aquilo que se encontrava no arcabouço do pensamento moderno; a valorização e a proteção do ser humano ${ }^{15}$.

\footnotetext{
${ }^{10}$ Ibid. p. 392.

${ }^{11}$ STRENGER, Irineu. Aplicação de normas de ordem pública nos laudos arbitrais. In: Revista dos Tribunais. Ano 75 - Abril de 1986 - Vol. 606. p. 11.

${ }^{12}$ BITTAR, Eduardo Carlos Bianca. O direito na pós-modernidade. Rio de Janeiro: Forense Universitária, 2005. p. 27.

${ }^{13}$ BAUMAN, Zygmunt. Modernidade líquida. Rio de Janeiro: Jorge Zahar Ed., 2001, passim.

14 CASELLA, Paulo Borba. Fundamentos do direito internacional pós-moderno. Tese de Titularidade apresentada à FADUSP: São Paulo, 2006. pp. 56 - 57.

${ }^{15}$ Ibid. p. 66.
} 
A imagem do patinador de Emerson ${ }^{16}$ que, ao enfrentar a tênue camada de gelo de um lago congelado, encontra na rapidez de seus movimentos a técnica necessária para deslizar de forma segura e seguir em frente serve, todavia, ainda inequivocamente à descrição dessa existência cada vez mais, com a licença do lugar-comum, globalizada, veloz e uniformizante. O prefixo "pós", portanto, parece servir, nesse contexto e ao menos pontualmente, tão somente à reafirmação da modernidade.

O mundo se torna dia após dia menor, as relações humanas são hoje transnacionais, multiconectadas, produto direto da técnica, das máquinas, do apreço à razão e à tecnologia ${ }^{17}$. O direito e a sociologia se ocupam cada vez mais da relação entre o local e o global, entre o geral e o específico, o universal e o relativo, o uniforme e o multicultural. Alguns se posicionam firmemente em defesa da sobreposição do geral ao local, outros defendem a diversidade acusando defeitos na uniformização, mas tanto em um quanto no outro grupo existem aqueles que claramente tentam refinar o discurso e harmonizar aquilo que aparentemente surge como antagônico e inconciliável.

Destacam-se nessa perspectiva conciliadora, como marcos referenciais centrais deste trabalho, a hermenêutica diatópica proposta ao diálogo intercultural cosmopolita por Boaventura de Sousa Santos, o conceito de dignidade humana na sistemática de direitos humanos vislumbrada por Ronald Dworkin e as teorias do maximalismo e do minimalismo moral aplicadas à política internacional por Michel Walzer.

Exatamente sob a perspectiva dessa conciliação lógica observável entre o universalismo e o relativismo cultural dos direitos humanos encontra-se a conjugação das três teorias contemporâneas que se apresenta na fundamentação dos resultados propostos nesse trabalho, a saber, a hermenêutica diatópica de Boaventura de Sousa Santos, o conceito de "certa atitude" de Ronald Dworkin aplicável à idéia de dignidade humana e os máximos e mínimos morais de Michael Walzer.

A pretendida harmonização entre o local e o geral - entre a visão universalista e a multiculturalista dos direitos humanos - tem como ponto de partida a concepção dialógica

\footnotetext{
${ }^{16}$ EMERSON, Ralph Waldo. Essays and lectures. New York: The Library of América, 1982. p. 364, em seu ensaio Prudence de 1841, "in verbis": "In skating over thin ice, our safety is in our speed".

${ }^{17}$ KENNEDY, David. The international human rights movement: part of the problem? In: Harvard Human Rights Journal. Vol. 15, 2002. p. 116.
} 
da hermenêutica diatópica de Santos, a qual se baseia essencialmente na conciliação como vértice do diálogo intercultural. A comunicação multicultural pela aceitação do estranho, da tópica diversa, pressupõe, entretanto, que todas as culturas possuam concepções de dignidade humana sem que houvesse entre elas uniformidade de conteúdo. Outro dado central da proposta do autor lusitano tem lugar no reconhecimento da incompletude das culturas e, portanto, da necessidade de abertura ao diálogo intercultural àquilo que se chamaria cosmopolitismo.

A universalidade do reconhecimento da dignidade da pessoa humana - estabelecida como fundamento lógico do diálogo intercultural - representa um dos pontos mais delicados da proposta diatópica e exige uma elaboração um pouco mais profunda de sua estruturação. Exatamente nessa lacuna da teoria de Santos e considerada a dignidade um dos objetos essenciais da doutrina da proteção dos indivíduos, surge o conceito de direitos humanos de Ronald Dworkin, baseado no direito de ser tratado com certa atitude, como admissível sustentáculo teórico dessa premissa essencial.

$\mathrm{O}$ autor norte-americano centra sua idéia de garantias basilares no direito irrenunciável do homem de ser tratado de forma equânime e previamente estabelecida pelas práticas e legislações vigentes no âmbito local das comunidades de indivíduos. Verifica-se, portanto, que, na teoria de Dworkin, o direito ao tratamento equânime teria, por um lado, víeis formal universalista, mas delegaria ao âmbito local, relativista, a dotação de conteúdo, a aferição da substância desse tratamento.

A relação proposta permite, finalmente, que se lance mão dos mínimos e máximos morais de Michel Walzer como instrumentos absolutamente hábeis à sedimentação da harmonização dessas duas perspectivas iniciais. Dessa feita, o minimalismo moral, compartilhamento geral de um núcleo essencial reduzido de valores por toda a humanidade, se mostraria plenamente aplicável ao discurso universalista visível em elementos de ambas as construções dos direitos humanos associadas, enquanto o maximalismo moral, de outro lado, cuidaria da fundamentação dos aspectos multiculturalistas, é dizer, das preocupações locais ali igualmente contidas ${ }^{18}$.

\footnotetext{
${ }^{18}$ DONNELLY, Jack. Universal human rights in theory and practice. Ithaca: Cornell University Press, 1989. p.113.
} 
A conciliação entre o universalismo e o relativismo cultural, fundada de forma sucinta na identificação de um procedimento global localmente preenchido de substância, surge cada vez mais como solução plausível à dificuldade de superação do distanciamento entre o geral e o localizado, a qual se constrói lentamente sobre uma visão sustentada na universal relatividade dos direitos humanos e apta a garantir sua efetiva proteção ${ }^{19}$.

A estrutura eminentemente principiológica dos direitos humanos, matriz de sua forte carga axiológica, faz com que seus preceitos sejam freqüentemente instados a solucionar questões jurídicas que exijam denso trabalho hermenêutico. Os desdobramentos desse contexto, decorrente do próprio reconhecimento da importância do ser humano pela doutrina jurídica, tornam possível que se vislumbre, portanto, a aplicação desse feixe de valores consagrados pelos direitos do homem à proteção da ordem pública instituída na sistemática do direito internacional privado ${ }^{20}$.

Nessa linha, a ordem pública conforma hoje em seus limites o conjunto dos princípios basilares do foro, ou seja, do ordenamento jurídico confrontado com a necessidade de observância de direito ou de ditames jurisdicionais alienígenas e exatamente nessa percepção da ordem pública - em seu entendimento como expressão da moralidade local - encontra-se a possibilidade de vinculação de sua essência à doutrina da proteção do ser humano.

Não se trata, na verdade, de uma proposta de mero traslado do debate dos direitos humanos aos conflitos de lei e de jurisdição, mas da assunção do papel informador desses direitos como pressuposto hermenêutico vinculante do estabelecimento dos contornos da ordem pública local hábil a trazer mais segurança à aferição da necessidade de sua proteção.

Diversos questionamentos podem surgir quando da imersão do mandamento de proteção da ordem pública do direito internacional privado na teoria dos direitos humanos e as próprias estruturas dos dois ramos do direito apresentam, de plano, obstáculos aparentemente intransponíveis a sua correlação em vista do caráter essencialmente

\footnotetext{
${ }^{19}$ Ibid. p. 124.

${ }^{20}$ LOUSSOUARN, Y.; BOUREL, P. Droit international privé. Paris: Dalloz, 1980. p. 13.
} 
substancial das garantias humanas e da vocação de sobre-direito do direito internacional privado.

Não seria difícil perceber, entretanto, a possibilidade de se cotejar a exceção que repele o direito alienígena com a proposta multiculturalista dos direitos humanos, posto que quando o magistrado aplica o instituto de direito internacional privado para afastar a eficácia de preceito estrangeiro nada mais faz que contrapor seu localismo ao alienígena para reafirmar, finalmente, seus máximos morais locais.

O problema central da comunhão teórica proposta não reside, contudo, na possibilidade de se relacionar os direitos humanos a uma parte específica do direito internacional privado, mas na possibilidade de se estabilizar o conteúdo da ordem pública do direito internacional privado e, assim, orientar de maneira mais precisa e técnica sua aplicação ao caso concreto $^{21}$.

Diversos são os doutrinadores que resistem à possibilidade de delimitação do conteúdo da ordem pública, objeto da proteção insculpida na sistemática do direito internacional privado ${ }^{22}$, mas mesmo quando assumida postura tendente a desconhecer o estabelecimento de limites científicos e definidos ao instituto ${ }^{23}$, muitos vislumbram os perigos dessa indefinição e, ao mesmo tempo, a possibilidade de uniformização, ao menos, dos aspectos formais de sua aplicação. ${ }^{24}$

A resistência relatada deve ser primeiramente entendida para que se possa, então, admitir a incompatibilidade da correlação aqui proposta. Nesse sentido, observa-se que a majoritária teoria do direito internacional privado repele a estabilização, é dizer, o engessamento da ordem pública, considerada como a expressão dos valores de uma sociedade em determinado contexto temporal e espacial e sujeita a um processo de constante mutação.

Ora, em nenhum momento encontram-se, entretanto, argumentos contrários à utilização de vetores interpretativos hábeis a auxiliar a determinação do conteúdo da ordem

\footnotetext{
${ }^{21}$ BARTIN, Principes de droit international privé. Paris, Éditions Domat- Montcherestien, 1930. p. 266-267. ${ }^{22}$ CASTRO, Op. cit., nota 01, p. 223.

${ }^{23}$ HEALY, Thomas H.. Théorie générale de l'ordre public. Recueil des Cours de la Académie de Droit International. Volume 9, 1925-IV. p. 474.

${ }^{24}$ Ibid. p. 546.
} 
pública, mas apenas reações à possibilidade de petrificação dessa essência. Exatamente valendo-se dessa constatação, torna-se absolutamente possível transpor o discurso dos direitos humanos de maneira eficaz ao direito internacional privado e, mais especificamente, a seu mecanismo excepcional de descarte da ordem jurídica alienígena.

Frise-se, ainda, que as próprias características do discurso dos direitos humanos podem contribuir a sua utilização como vetor hermenêutico pelos demais ramos do direito e não haveria como se negar certa facilidade à transposição da textura aberta de seus princípios à determinação da ordem pública do direito internacional privado ${ }^{25}$.

Mais do que a possibilidade de diálogo entre a moralidade contida na ordem pública e a doutrina dos direitos humanos, as semelhanças entre os institutos torna possível a constatação de verdadeira correspondência entre as características do mecanismo aplicável ao conflito de leis e de jurisdições e o núcleo protetivo mínimo atribuído aos seres humanos.

Tal correlação ganha contornos bastante cristalinos na concepção de direitos humanos que resulta da combinação da hermenêutica diatópica construída sobre o diálogo intercultural idealizado por Santos com o conceito de dignidade humana de Dworkin e da utilização dos máximos e mínimos morais de Walzer para compatibilizar tais instrumentais teóricos de forma adequada.

Permitir a eficácia de direito estrangeiro ou de decisão emanada por órgão jurisdicional alienígena no foro em nada mais consistiria, mutatis mutandis, do que em forma de assunção da incompletude do ordenamento jurídico local que, na busca pelo melhor direito, encontraria no diálogo intercultural a solução de casos concretos.

A adoção dessa perspectiva cosmopolita significa na doutrina dos direitos humanos a conversão do embate entre localismos em diálogo apto a promover a proteção do ser humano globalmente sem que as idiossincrasias locais sejam desconsideradas. Nesse sentido, o significado de dignidade humana se daria, na tópica diversa, mediante a harmonização do local com o exógeno, mas exigiria que as diversas culturas envolvidas

\footnotetext{
${ }^{25}$ CANÇADO TRINDADE, Antônio Augusto. O direito internacional em um mundo em transformação. Rio de Janeiro: Renovar, 2002. p. 639.
} 
compartilhassem um conceito básico comum de dignidade plenamente aplicável aos parâmetros fundantes de cada moralidade local.

Nesse ponto específico da hermenêutica diatópica, constata-se absoluta correspondência de seu padrão com a sistemática do direito internacional privado, na qual os parâmetros locais elementares estariam sob o escudo protetor da ordem pública. Assim, considerada a importância dos direitos humanos e aplicada a doutrina cosmopolita de Santos ao direito internacional privado, a proteção da ordem pública se apresentaria como importante instrumento do diálogo intercultural e não como mera exceção de repulsa de atentados à moralidade do foro.

A impossibilidade de estabilização substancial traduz, conforme mencionado, característica marcante tanto do discurso aberto dos direitos humanos quanto da instável perspectiva da ordem pública do direito internacional privado e, por essa razão, a generalização da concepção de dignidade humana do diálogo cosmopolita exige a aplicação de um suporte hábil a sua aferição.

Exatamente nesse momento e com essa função apresenta-se nessa dinâmica a perspectiva dworkiana da dignidade humana, a qual se funda no direito ao tratamento em conformidade com "certa atitude", ou seja, de o indivíduo ser tratado de maneira equânime e previamente estabelecida pelas práticas e legislações vigentes no âmbito local de cada uma das comunidades humanas. Transportada ao direito internacional privado, tal teoria mostra-se perfeitamente apta a desenhar os limites da ordem pública e a inserir a perspectiva protetiva do conflito de leis e de jurisdições na doutrina da primazia da proteção do indivíduo.

\section{A Ordem Pública Nacional e a Constituição}

As controvérsias relacionadas ao reconhecimento e à proteção de direitos inerentes à condição humana, muito antes do debate substancial, têm lugar nas dificuldades causadas pelas inúmeras nomenclaturas utilizadas para indicá- $\operatorname{los}^{26}$. Direitos humanos, direitos da pessoa humana, garantias individuais e direitos fundamentais são apenas alguns dos termos

\footnotetext{
${ }^{26}$ SILVA, José Afonso da. Curso de direito constitucional positivo. São Paulo: Malheiros, 1998. p. 179.
} 
adotados para denominar - algumas vezes com nuances de conteúdo - o núcleo de direitos vinculados à essência da existência do indivíduo.

Passo importante na compreensão da evolução e da consagração dessas garantias se dá na observação da forma como os ordenamentos jurídicos locais, ao estabelecerem direitos fundamentais inegociáveis ${ }^{27}$, dialogam com a doutrina da proteção internacional dos direitos humanos ${ }^{28}$. Mencionada análise pressupõe, entretanto, a preliminar caracterização da maneira como ocorreu o reconhecimento dos direitos do homem e, mais diretamente, o estudo do papel da positivação nesse processo.

No caso específico dos direitos humanos, a positivação teve lugar inicialmente na incorporação de garantias individuais às declarações de direito modernas e às constituições dos Estados-nacionais que se seguiram ${ }^{29}$. Os movimentos de constitucionalização se destacaram dentre os aspectos fundantes dessas conquistas ${ }^{30}$ e as garantias inicialmente declaradas em documentos sem força vinculante não foram, em sua grande maioria, positivadas internamente em meros textos legais, mas acabaram sendo introduzidas no corpo das constituições que então surgiam ${ }^{31}$.

Nas estruturas eminentemente hierárquicas da técnica jurídica moderna - modelo ainda predominante atualmente - as garantias individuais estabeleceram-se de forma gradual no topo das pirâmides normativas dos ordenamentos jurídicos e, mediante paulatino desenvolvimento das técnicas interpretativas, acabaram adquirindo força cogente e passaram, via de regra, a vincular, como no caso brasileiro, todo o sistema legal abaixo delas.

\footnotetext{
${ }^{27}$ Nomenclatura utilizada aqui em referência aos direitos humanos protegidos no plano interno dos países consoante, por exemplo, CAGGIANO, Monica Herman S. Os direitos fundamentais e sua universalização. In: Revista Brasileira do Direito Constitucional, n. 4, jul./dez., 2004, p. 760, mas utilizada também com outra acepção, como veremos abaixo.

${ }^{28}$ PIOVESAN, Flávia. Direitos humanos e o direito constitucional internacional. São Paulo: Editora Max Limonad Ltda., 1996. p. 253.

${ }^{29}$ BOBBIO, Norberto. Teoria geral da política - a filosofia e as lições dos clássicos. Trad. Daniela Beccaccia Versiani. Rio de Janeiro: Campus, 2000. p. 481.

${ }^{30}$ SILVA, Op. cit., nota 26. p. 171.

${ }^{31}$ CANOTILHO, J.J. Gomes. Direito constitucional e teoria da constituição. Coimbra: Almedina, 2003. p. 377.
} 
No Brasil, a definitiva consolidação dos direitos humanos no plano interno ocorreu com a promulgação da Constituição Federal de $1988^{32}$, a qual possui como núcleo central os chamados direitos fundamentais expressos principalmente no arcabouço principiológico contido em seus primeiros artigos e especialmente no corpo de seu extenso artigo quinto.

Da leitura da carta de direitos brasileira percebe-se nítida opção do legislador originário pela textura aberta da terminologia empregada na redação desses princípios fundamentais, os quais, muitas vezes, estabelecem garantias que necessitam de atividade legislativa ordinária ou de forte trabalho hermenêutico efetuado no caso concreto para a aquisição da devida eficácia. A amplitude conceitual dos direitos fundamentais constitui hoje, de fato, uma de suas maiores características e exatamente valendo-se de toda essa plasticidade $^{33}$ surge a adaptabilidade funcionalizadora de seu papel hermenêutico ${ }^{34}$.

Em síntese, o tratamento dispensado ao ser humano não poderia no Brasil ir de encontro aos direitos fundamentais e, inclusive, à interpretação jurisprudencial a eles dada, ambos elementos que conformariam, portanto, a atitude com a qual o ser humano teria o direito de ser tratado segundo os usos e as leis brasileiras. A constituição federal e mais especificamente os direitos fundamentais ali contidos consubstanciariam, assim, no contexto nacional a "certa atitude" da qual se extrairia, segundo as teorias de Ronald Dworkin, a essência da dignidade humana em determinado localismo.

Os direitos superiores, fundamentais, estabelecidos pelo constituinte originário na carta constitucional de 1988, traduziriam a moralidade fundante do Estado brasileiro e informariam, por conseguinte, o conceito nuclear da moralidade local, o qual deve, por sua vez, ser levado em conta, segundo o instrumental teórico aqui proposto, no diálogo intercultural, é dizer, no momento da aferição do conteúdo da ordem pública que exigiria, no caso concreto, a repulsa da lei estrangeira como instrumento protetivo da moralidade do foro.

\footnotetext{
${ }^{32}$ SARLET, Ingo Wolfgang. A eficácia dos direitos fundamentais. Porto Alegre: Livraria do Advogado, 2003.. p. 74 .

${ }^{33} \mathrm{~A}$ utilização do termo "plástica" aqui não se refere necessariamente à classificação das constituições pela plasticidade, mas tão somente à adaptabilidade vislumbrada.

${ }^{34}$ KLATAU FILHO, Paulo. Universalismo versus relativismo cultural - Legitimidade da concepção cosmopolita dos direitos humanos. In: Revista Brasileira de Direito Constitucional. São Paulo, n. 4, jul./des. 2004, p. 73, "in verbis": "Tais direitos [fundamentais] e suas garantias nada mais são do que a positivação constitucional de valores reconhecidos pela sociedade."
} 
Independentemente da vinculação da ordem pública nacional aos direitos humanos e, conseqüentemente, aos direitos fundamentais constitucionalmente garantidos, o magistrado instado a aplicá-la para afastar a eficácia de lei ou de decisão estrangeira estaria, conforme anteriormente mencionado, obrigado a fundamentar sua decisão ${ }^{35}$. Com a identificação da absoluta identidade entre a moralidade local, objeto do instituto protetivo de direito internacional privado, e as garantias constitucionais, a motivação da opção pela aplicação da exceção da ordem pública ganharia novos contornos e passaria a exigir, necessariamente, argumento constitucional balizador.

Confrontado com direito ou pronunciamento alienígena, o magistrado nacional apenas poderia afastá-lo, assim, caso verificasse lesão a preceito constitucional fundamental hábil a preencher o conteúdo relativo e instável da ordem pública nacional. A aplicação da exceção de direito internacional fora desses limites apresentaria vício caracterizador de nulidade passível de declaração de inconstitucionalidade.

\section{Conclusão}

A pesquisa aqui apresentada teve como ponto de partida e motriz principal as características de instabilidade e relatividade apontadas pela majoritária doutrina à ordem pública do direito internacional privado. Nesse sentido, observou-se preliminarmente que, se por um lado, o desenvolvimento teórico do instituto consolidou seu conteúdo ao longo dos anos como síntese do núcleo moral inegociável de determinada ordem jurídica, sua aplicação não logrou, entretanto, estabelecer, ainda, um parâmetro consistente à aferição da essência da moralidade nele contida.

Por essa razão, percebe-se que a função de verdadeiro escape garantidor dos valores essenciais do foro exercida pela proteção da ordem pública na sistemática do conflito de leis e de jurisdições acaba sendo atualmente - na falta de técnica segura e previsível e em razão de sua amplitude - submetida à discricionariedade judicial de forma quase irrestrita. A condescendência doutrinária com essa característica aberta do

\footnotetext{
${ }^{35}$ CINTRA, Antônio Carlos de Araújo; GRINOVER, Ada Pellegrini; DINAMARCO, Cândido R. Teoria geral
} do processo. São Paulo: Malheiros. p. 68. 
instrumento pode, contudo, ameaçar toda a estrutura do direito internacional privado, pois quando repelido o direito alienígena, repelida também é, necessariamente, a regra de conexão utilizada para apontá-lo e qualquer excesso jurisdicional em sua aplicação acaba tendendo a enfraquecer a própria técnica que justifica seu uso.

Nesse sentido, ainda que haja na legislação expressa previsão da proteção da ordem pública, justificada por toda a lógica protetiva e garantista da moralidade local, é de se perceber que tal reserva principiológica da jurisdição, na verdade, contradiz o direito internacional privado e possui, em razão da impossibilidade de pré-concepção de seu conteúdo e da importância do magistrado em sua concretização, nítida margem ao abuso em sua aplicação e, conseqüentemente, ao desmonte de todo o sistema que organiza a solução judicial das relações multiconectadas.

À luz de tais desafios, a proposta aqui desenvolvida baseou-se na transposição de doutrinas conciliadoras surgidas no âmbito do embate entre o multiculturalismo e o universalismo dos direitos humanos para o direito internacional privado, mais especificamente para o estudo da ordem pública do direito internacional privado e de sua exigida proteção.

O caráter concretista da ordem pública ganha contornos ainda mais especiais quando observado que a aferição de eventual lesão não poderia, em razão de sua identidade com a moralidade local em determinado contexto tempo-espacial, ser taxativamente elencada de maneira prévia pelo legislador, o qual tem historicamente deixado a cargo do aplicador do direito - é dizer do magistrado - a determinação de seu conteúdo e, portanto, da hipótese de incidência da exigibilidade de sua proteção.

A função do agente jurisdicional submete-se, entretanto, a limites, posto que o instituto, ainda que aberto, está contido na sistemática do direito internacional privado, o qual, por sua vez, se insere na racionalidade do ordenamento jurídico que compõe. Não se trata, assim, de hipótese de ampla discricionariedade hábil a possibilitar juízo de equidade, mas de necessária harmonização da decisão quanto ao atentado à ordem pública com os preceitos jurídicos do foro que a analisou.

Nesse contexto limitador surgem os importantes mandamentos constitucionais que exigem a motivação das decisões judiciais, extraíveis tacitamente dos incisos LIV e LV do 
artigo $5^{\circ}$ e de forma absolutamente expressa do artigo 93 da carta constitucional de 1988. Independentemente da existência de um direito subjetivo natural à justificação, o juiz tem hoje o dever legal de indicar claramente os elementos que o levaram a decidir o caso concreto e, ainda que ausentes dispositivos legais que justifiquem seu pronunciamento, subsistem, para tanto, toda a base principiológica do ordenamento e a construção costumeira extraível, por exemplo, da jurisprudência emanada pelos tribunais.

É de se concluir, portanto e inicialmente, que a orientação doutrinária tendente a outorgar plenos poderes à dotação de conteúdo à ordem pública ao aplicador do direito instado a verificar ataque à moralidade do foro mostra-se fatalmente equivocada, pois contraria a estruturação do direito internacional privado como parte de um todo jurídico submetido às premissas e ditames cogentes à integralidade do sistema.

O magistrado não possui, assim, a opção, mas, na verdade, o dever de fundamentar sua exclusão da ordem legal estrangeira por meio do reconhecimento de atentado à ordem pública de sua jurisdição em elementos principiológicos, hábeis a suportar a caracterização do núcleo moralmente relevante da sociedade, na qual ele se insere.

No caso específico do Brasil, reconhecidos os direitos humanos por meio da inserção dos direitos fundamentais na constituição federal de 1988, a moralidade local refletida na ordem pública que exige a proteção de repulsa estaria inexoravelmente contida na principiologia constitucional, a qual surge como justificativa necessária à aplicação do instituto pelo magistrado.

A abertura conceitual apontada pela doutrina do direito internacional privado à ordem pública não deve servir de argumento à inexistência de justificativa a sua aplicação para afastar o direito importado. A relatividade, maior característica da exceção, faz sentido, portanto, quando devidamente combinada com a contemporaneidade, isto é, com os fatores temporais e espaciais, os quais devem servir à sua definição e ser coerentemente justificados pelos princípios informadores da ordem jurídica.

Estabelecidas tais premissas e observada a irrelevância da classificação do instrumento internacionalista como vertente de aplicação de um conceito uno ou como instituto autônomo com características próprias, dois âmbitos de incidência tornam-se identificáveis à ordem pública; a ordem pública interna, relacionada à autonomia privada na 
perspectiva interna de determinada ordem legal, e a ordem pública do direito internacional privado, a qual se subdivide em ordem pública nacional, objeto de proteção quando o direito estrangeiro é indicado pela regra de conexão e a chamada ordem pública internacional, observável quando da concessão de efeitos no foro a pronunciamentos judiciais estrangeiros.

Tanto na delimitação das características do instrumento que exige o óbice do direito estrangeiro indicado na sistemática do direito internacional privado, quanto na identificação dos desafios da aferição de seu conteúdo e no reconhecimento da obrigatoriedade da justificação das decisões judiciais no ordenamento jurídico brasileiro encontram-se as premissas necessárias à transposição para o conflito de leis e de jurisdições de propostas interculturais conciliadoras concebidas no âmbito da relação entre as doutrinas do multiculturalismo e do universalismo dos direitos humanos.

Nesse sentido, ressalta-se a visível identidade de contornos existente entre o embate do relativismo cultural com o universalismo no discurso dos direitos do homem e os conflitos de leis e de jurisdição intrínsecos ao sistema do direito internacional privado e, por conseguinte, a extrema relevância de qualquer elaboração teórica que sirva para conciliar o global com o local e, principalmente, os diversos localismos entre si.

À concretização de tal proposta de transposição e com o propósito de se estabelecer limite claro à determinação da ordem pública do direito internacional privado surge o diálogo intercultural cosmopolita instrumentalizado na hermenêutica diatópica de Boaventura de Sousa Santos, a qual se sustenta na assunção da incompletude inerente a todas as culturas e na comunicação entre culturas não apenas como um meio, mas como uma necessidade de preenchimento dos vazios de cada uma das partes do todo global.

Essa perspectiva dialógica tem por base a inegociabilidade da dignidade humana, cujo conteúdo não constituiria um elemento universal, mas sintetizaria aspectos localmente determináveis. Como solução à amplitude do conceito de dignidade proposto por Santos surge, na esteira desse raciocínio, o direito de ser tratado com certa atitude, expressão com a qual Ronald Dworkin descreve o piso protetivo subjetivo mínimo do ser humano. Como elemento concatenador desse casamento teórico surgem finalmente as teorias do 
maximalismo e do minimalismo moral de Michael Walzer para a fundamentação do transbordo dessa proposta conceitual para a ordem pública do direito internacional privado.

Aplicada à ordem pública nacional, vertente da ordem pública do direito internacional privado incidente na indicação de lei alienígena à solução do caso concreto pelas regras de conexão do foro, os preceitos morais nucleares que exigiriam a repulsa da ordem jurídica estrangeira seriam, à luz do diálogo intercultural cosmopolita, aferidos a partir da atitude mediante a qual o ser humano tem o direito de ser tratado no âmbito da moralidade do foro. Importante ressaltar, ainda, que de extrema relevância nessa aferição seriam os máximos morais locais do magistrado instado a decidir no caso concreto.

No que se refere à ordem pública internacional, aplicável à decisão estrangeira que busca gerar efeitos no foro, o diálogo intercultural se dá em seu aspecto cosmopolita puro, periférico, baseado nos mínimos morais do foro, no conteúdo mínimo da certa atitude garantida ao ser humano por aquele localismo determinado.

Da aplicação dessa construção teórica fundada em conceitos complementares ao instituto de exceção do direito internacional privado conclui-se que sua instabilidade, a maior de suas características apontadas pela doutrina, se refere a sua plasticidade, sua adaptabilidade à época e ao local, no qual ele se localiza, mas não se traduziria na impossibilidade de se estabelecerem critérios menos subjetivos a sua aferição.

No ordenamento jurídico brasileiro especificamente, a atitude mediante a qual o ser humano tem o direito de ser tratado que informa a dignidade humana aplicável ao diálogo intercultural cosmopolita estaria expressamente inscrita no texto da constituição federal, cujos ditames nucleares não serviriam, sob tal lógica, apenas para orientar o magistrado instado a aplicar a proteção da ordem pública do direito internacional privado, mas, na verdade, vinculariam a fundamentação de seu pronunciamento.

Reconhecido o dever constitucional de motivação dos pronunciamentos judiciais e verificada a completa identidade da ordem pública com a construção teórica aplicável aos direitos humanos apontada, as quais se compatibilizam com critérios de prospecção de conteúdo orientados aos direitos listados no texto da carta constitucional, torna-se possível vislumbrar a vinculação do magistrado à constituição federal não como um diploma 
hermenêutico orientador, mas como um verdadeiro parâmetro que estabelece um elenco de direitos fundamentais que se impõem à fundamentação dos pronunciamentos judiciais.

Ao término desse trabalho, é de se estabelecer fundamentalmente, em síntese, que a exigência de motivação dos pronunciamentos judiciais que aplicam ou negam a necessidade da exceção de proteção da ordem pública do direito internacional privado encontra-se vinculada necessariamente à carta de direitos expressamente contida no texto constitucional, posto que tal instituto reativo, sintetizador da moralidade local, deve tão somente refletir a atitude, mediante a qual o indivíduo tem o direito de ser tratado no contexto jurídico brasileiro sob a perspectiva eminentemente cosmopolita que se impõe hodiernamente ao diálogo intercultural em um esforço conciliador entre os míninos gerais e os máximos de cada localismo envolvido.

\section{Bibliografia}

BARTIN, E. Principes de droit international privé. Paris, Éditions DomatMontcherestien, 1930.

BAUMAN, Zygmunt. Modernidade líquida. Rio de Janeiro: Jorge Zahar Ed., 2001. BITTAR, Eduardo Carlos Bianca. O direito na pós-modernidade. Rio de Janeiro: Forense Universitária, 2005.

BOBBIO, Norberto. Teoria geral da política - a filosofia e as lições dos clássicos. Trad. Daniela Beccaccia Versiani. Rio de Janeiro: Campus, 2000.

CAGGIANO, Monica Herman S. Os direitos fundamentais e sua universalização. In: Revista Brasileira do Direito Constitucional, n. 4, jul./dez., 2004.

CANÇADO TRINDADE, Antônio Augusto. Tratado de direito internacional dos direitos humanos - vol. I. Porto Alegre: Sergio Antonio Fabris Editor, 1997.

CANOTILHO, J.J. Gomes. Direito constitucional e teoria da constituição. Coimbra: Almedina, 2003.

CASELLA, Paulo Borba. Fundamentos do direito internacional pós-moderno. Tese de Titularidade apresentada à FADUSP: São Paulo, 2006.

Direito internacional privado. Rio de Janeiro: Forense, 2005.

CINTRA, Antônio Carlos de Araújo; GRINOVER, Ada Pellegrini; DINAMARCO, Cândido R. Teoria geral do processo. São Paulo: Malheiros, 2000.

Direito internacional privado: parte especial - Direito civil internacional - vol.

II - Contratos e obrigações no direito internacional privado. Rio de Janeiro: Renovar, 2007.

DONNELLY, Jack. Universal human rights in theory and practice. Ithaca: Cornell University Press, 1989.

DWORKIN, Ronald. Law's empire. Cambridge/London: Harvard University Press, 1986. 
2006.

Is democracy possible here? Princeton and Oxford: Princeton University Press, EMERSON, Ralph Waldo. Essays and lectures. New York: The Library of América, 1982.

FERREIRA, Vasco Taboada. Princípios fundamentais dos sistemas de direito internacional privado português e brasileiro. Braga: Livraria Cruz, 1960.

HEALY, Thomas H.. Théorie générale de l'ordre public. Recueil des Cours de la Académie de Droit International. Volume 9, 1925-IV. pp. 407-557.

KENNEDY, David. The international human rights movement: part of the problem? In: Harvard Human Rights Journal. Vol. 15, 2002. p. 101 - 125.

KLATAU FILHO, Paulo. Universalismo versus relativismo cultural - Legitimidade da concepção cosmopolita dos direitos humanos. In: Revista Brasileira de Direito Constitucional. São Paulo, n. 4, jul./des. - 2004.

NIBOYET, J.-P. Notions sommaires de droit international privé en vue de l'examen de licence. Paris: Recueil Sirey, 1937.

PIOVESAN, Flávia. Direitos humanos e o direito constitucional internacional. São Paulo: Editora Max Limonad Ltda., 1996.

RECHSTEINER, Beat Walter. Direito internacional privado - teoria e prática. São Paulo: Saraiva, 2007.

SANTOS, Boaventura de Souza. Uma concepção multicultural de direitos humanos. In: Lua Nova: Revista de Cultura e Política 39, 1997, pp. 105-124.

SARLET, Ingo Wolfgang. A eficácia dos direitos fundamentais. Porto Alegre: Livraria do Advogado, 2003.

SAVATIER, René. Cours de droit international privé. Paris: Librarie Générale de Droit et de Jurisprudence, 1947.

SILVA, José Afonso da. Curso de direito constitucional positivo. São Paulo: Malheiros, 1998.

STRENGER, Irineu. Aplicação de normas de ordem pública nos laudos arbitrais. In: Revista dos Tribunais. Ano 75 - Abril de 1986 - Vol. 606. pp. 09-12.

. Direito internacional privado. São Paulo: Ltr, 2005.

TIBURCIO, Carmen. Temas de Direito Internacional. Rio de Janeiro: Renovar, 2006.

WALZER, Michael. Thick and thin, moral argument at home and abroad. Notre Dame: undp, 1994. 